\title{
Integration of Distributed Generations in Radial Distribution Network using ABC Algorithm
}

\author{
Rajni Bala, Smarajit Ghosh
}

\begin{abstract}
This paper keeps aim to integrate distributed generations(DGs) in radial distribution networks (RDNs) using $A B C$ algorithm. The appropriate nodes of $R D N$ is found out by the well-established loss sensitivity index. The optimal size of DGs are found out by using the $A B C$ algorithm. The optimal integration of DGs not only reduces the loss but also increases the voltage profile and enhances the voltage stability index and hence improves the stability of the system. Here 33-node and 69-node RDNs are considered to implement the proposed method. The outcomes obtained by ABC algorithm have also been compared with that Firefly, PSO and GA algorithms.
\end{abstract}

Keywords : ABC,FF, GA, PSO, LSF, DG, RDN

\section{INTRODUCTION}

The electrical utility network is generally separated into three subsystems, which are production, transmission, and distribution. A fourth separation, is sub transmission, that is created sometimes. Distribution has an essential influence as the purchasers are specifically influenced by its effectiveness. Extending a current network by adding feeders newly or by reconfiguring the distribution feeders of the existing network and also by constructing substations newly, these all are included in the normal Distribution System Planning (DSP). If the distributed generator (DG) isn't huge, the DG incorporation in distribution system planning reduces the cost of planning as it creates DSP models newly. The installation time is very less and additionally it supports the distribution delay and transmission [1]. Electrical distribution networks are becoming complicated and huge, which paves the way for low regulation of voltage and greater system losses. Among the power system customers and the distribution substation, distribution network is presented [2]. It contains of a number of analogous radial circuits. Considering the greatest load requirement, the distribution networks are premeditated. Almost all the traditional power distribution systems are provided with radial networks by means of one way power flow [3]. Power flow analysis is one of the significant and primary apparatus. The upcoming

Revised Manuscript Received on October 30, 2019.

* Correspondence Author

Rajni Bala*, Department of Electrical Engineering, Baba Banda Singh Bahadur Engineering College, Fatehgarh Sahib, Punjab-140407, India. E-mail: rajni.bala@bbsbec.ac.in, rajnibala8880@gmail.com

Smarajit Ghosh, Department of Electrical and Instrumentation Engineering, Thapar Institute of Engineering and Technology, Patiala-147004, Punjab $\quad$ E-mail: sghosh@thapar.edu, smarajitg@hotmail.com

(C) The Authors. Published by Blue Eyes Intelligence Engineering and Sciences Publication (BEIESP). This is an open access article under the CC BY-NC-ND license (http://creativecommons.org/licenses/by-nc-nd/4.0/)

expansion of the network is based upon the distribution system load flow analysis as the requirement of load is further enhanced. Steady state condition of a system can be attained by the load stream resolution [4]. Reducing losses in power distribution systems is an imperative requirement, because if they exceed the losses concern [5].

Jia et al. [6] had presented any hierarchical solution to evaluate the impact of alteration with the distribution system in power system threat evaluation. DGs may present critical loads within the distribution system through re-dispatching right after a few concurrent takes place.

Mohamed and Kowsalya [7] had exhibited a novel method to find the most ideal size and area of DG with system power losses minimization, operational expenses and making upgrades to voltage stability as a goal. Loss sensitivity factor (LSF) was used to decide the ideal locations of DG units' placement. Bacterial Foraging Optimization Algorithm (BFOA) used to seek out the DG ideal size.

Murty and Kumar [8] had given an assessment of new power loss sensitivity, power stability index (PSI), and voltage sensitivity index (VSI) approaches for ideal size and location of DG in the distribution system. Hung and Mithulananthan [9] had examined the difficulty in a numerous, DG elements settlement for attaining loss reduction in large-scale radial distribution networks (RDNs). Doagou-Mojarrad et al. [10] had introduced an intelligent fuzzy fulfilling strategy, which depended on Hybrid Modified Shuffled Frog Leaping Algorithm, and tackled the issue of the Multi-objective ideal position and estimating of DG units. Imran et al. [11] had exhibited a novel combination method for ideal system reconfiguration and distributed generation (DG) situation in distribution network with a goal of power loss minimization and voltage stability improvement.

\section{METHODOLOGY}

For estimating reputable and accurate results of a system, the load flow study is taken into consideration. The estimation of a distribution system voltage, current and power flows throughout the system are included in the load flow study. Voltage profile is the most important information obtained from the load flow analysis [12]. Measurement of voltage and current in the distribution system is the major thing in the analysis of load flow. These measurements are done by using (1) and (2).

$$
\begin{aligned}
\left|V_{m+1}\right|^{2}= & \left|V_{m}\right|^{2}+\frac{R_{m, m+1}^{2}+X_{m, m+1}^{2}}{\left|V_{m}\right|^{2}}\left(P_{m, m+1}^{2}+Q_{m, m+1}^{2}\right) \\
& -2\left(R_{m, m+1} P_{m, m+1}+X_{m, m+1} Q_{m, m+1}\right)
\end{aligned}
$$

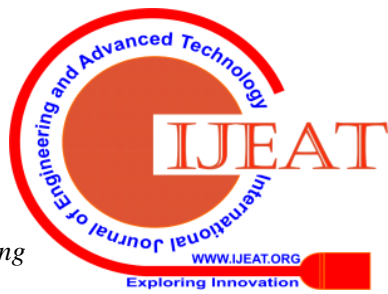




$$
I_{m, m+1}=\sqrt{\frac{P_{m, m+1}^{2}+Q_{m, m+1}^{2}}{\left|V_{m}\right|^{2}}}
$$

The system's total real power loss associated with the branches between the node $\mathrm{m}$ and $\mathrm{m}+1$ can be defined as

$$
P_{T L}=\sum_{n=1}^{N B} P_{\text {Loss }}(m, m+1)
$$

The summation of power losses associated with each branch of the RDN is denoted as the total loss of the system having a total NB number of branches.

The total active power loss is expressed in (4)

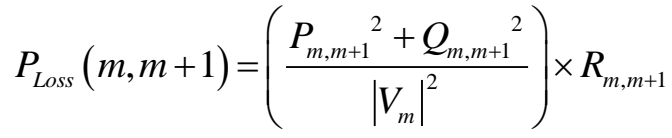

The total reactive power loss is expressed in (5)

$$
Q_{\text {Loss }}(m, m+1)=\left(\frac{P_{m, m+1}{ }^{2}+Q_{m, m+1}^{2}}{\left|V_{m}\right|^{2}}\right) \times X_{m, m+1}
$$

\section{Constraints}

\section{Limit for voltage deviation}

The bus voltage for each node in RDN should be maintained within a prescribed limit is specified by (6).

$$
V_{m, \min } \leq\left|V_{m}\right| \leq V_{m, \max }
$$

Where the minimum and maximum values of voltage magnitudes are $\mathrm{V}_{\mathrm{m} \text {,min }}$ and $\mathrm{V}_{\mathrm{m} \text {,max }}$.

\section{Current capacity limit of RDN feeder}

The current flow of the each branch of the feeder must be within the prescribed limit.

$$
I_{m, m+1} \leq I_{m, m+1} \max \quad m=1,2, \ldots \ldots . . N B
$$

\section{DG sizing limit}

The real power injected into the system by using the DG is limited between minimum and maximum values of DG unit size placed.

$$
P_{\text {minimum }}{ }^{D G} \leq P_{i}^{D G} \leq P_{\text {maximum }}{ }^{D G}
$$

The minimum and maximum size of the DG unit is described as follows.

$$
\begin{gathered}
P_{\text {minimum }}{ }^{D G}=0.1 \sum_{i=2}^{m} P_{i}^{D G} \\
P_{\text {maximum }}^{D G}=0.8 \sum_{i=2}^{m} P_{i}^{D G}
\end{gathered}
$$

The loss sensitivity factor is available in [12].

Artificial bee colony (ABC) procedure $[13,14]$ is a standout amongst the most as of late presented swarm-based calculations. ABC mimics the wise searching conduct of a honeybee swarm. The execution of the ABC is superior to or like those of other population based calculations with the benefit of utilizing less control parameters. The behavior of real bees is given as follows and from that the $A B C$ optimization algorithm is constructed.

1. Food Sources: In request to choose a food source, a forager bee assesses a few properties related with the food source, for example, its closeness to the hive, wealth of the vitality, taste of its nectar, and the simplicity or trouble of extricating this vitality. For the straightforwardness, the nature of a food source can be spoken to by just a single amount despite the fact that it relies upon different parameters referenced previously.
2. Utilized foragers: An utilized forager is utilized at a particular food source which she is as of now misusing. She conveys data about this particular source and offers it with different bees holding up in the hive. The data incorporates the separation, the course and the benefit of the food source. 3. Jobless foragers: A forager bee that searches for a food source to misuse is called jobless. It tends to be either a scout who searches the earth arbitrarily or a passerby who attempts to discover a food source by methods for the data given by the utilized bee. The mean amount of scouts is around $5 \%-10 \%$. The trading of data among bees is the most essential event in the development of aggregate information. While looking at the whole hive it is conceivable to recognize a few sections that regularly exist in all hives. The most essential piece of the hive as for trading data is the moving zone. Correspondence among bees identified with the nature of food sources happens in the moving region. The related move is called waggle move.

In the ABC calculation, the artificial bees are arranged into three gatherings as expressed over: the utilized bees, the onlookers and the scout. Bee that misusing a food source is named utilized. The utilized bees share data with the onlooker bees, which are holding up in the hive and viewing the occasions of the utilized bees. The passer-by bees at that point pick a food source with likelihood relative to the nature of food source. The great food sources pull in a greater number of bees than the awful ones. Scout bees chase for new food sources arbitrarily in the region of the hive. At the point when a scout or onlooker bee gets a food source, it winds up utilized. At the point when a food source has been completely abused, all the utilized bees related with it will surrender the position, and may move toward becoming scouts once more. In this way, scout bees play out the activity of "investigation", though utilized and passer-by bees play out the activity of "abuse". The tasks in scout bee is performed by using Cuckoo Search (CS) Algorithm, which encourages crafted by the scout bee stage increasingly robust. In the proposed calculation, a food source relates to a conceivable answer for the streamlining troubles, and the nectar measure of a food source compares to the wellness of the related arrangement. In $\mathrm{ABC}$, the principal half of the colony comprise of utilized bees and the other half are onlookers. The quantity of utilized bees is equivalent to the quantity of food sources (SN) since it is accepted that there is just a single utilized bee for every food source. In this way, the quantity of onlooker bees is likewise comparable to the quantity of arrangements under thought. The ABC calculation starts with a gathering of arbitrarily produced food sources. The principle methodology of ABC can be portrayed as pursues.

Stage 1: Initialize the food sources.

Stage 2: Each enlarged bee begins to deal with a food source. Stage 3: Each Onlooker bees chooses a food source as indicated by the nectar data shared by the employed.

Stage 4: Determine the Scout bees, which will search for food sources in a random way.

Stage 5: Test whether the termination condition is met or not. If not, return to Step 2. 


\section{RESULTS}

The proposed method is implemented on two radial distribution networks (33-node and 69-node) both having $12.66 \mathrm{kV}$ and $100 \mathrm{MVA}$ as base values.

At first 33-node RDN is considered. The base case results are $202.52 \mathrm{~kW}, 135.10 \mathrm{kVAr}$, the minimum voltage 0.9132 p.u. at node number $18, \mathrm{VSI}_{\min }=0.83411$ at node number 18 . Table I shows the outcomes of 33-node RDN after placement of three DGs using ABC, Firefly (FF), GA and PSO algorithms. The locations of DGs are 13,25 and 30.Table I. Outcomes of 33-node RDN

\begin{tabular}{|l|l|l|l|l|}
\hline $\begin{array}{l}\text { Three } \\
\text { DGs by } \\
\text { the } \\
\text { algorithm }\end{array}$ & $\begin{array}{l}\text { Total } \\
\text { DG } \\
\text { size } \\
(\mathrm{MW})\end{array}$ & $\begin{array}{l}\text { Real } \\
\text { Power } \\
\text { Loss } \\
(\mathrm{kW})\end{array}$ & $\begin{array}{l}\text { Minimum } \\
\text { voltage } \\
\text { (p.u.) and } \\
\text { Node } \\
\text { number }\end{array}$ & $\begin{array}{l}\text { VSI and } \\
\text { Node } \\
\text { number }\end{array}$ \\
\hline ABC & 2.77 & 72.16 & $0.9732(33)$ & $0.9376(33)$ \\
\hline Firefly & 2.80 & 73.22 & $0.9712(33)$ & $0.9343(33)$ \\
\hline PSO & 2.83 & 74.42 & $0.9692(33)$ & $0.9317(33)$ \\
\hline GA & 2.87 & 75.58 & $0.9670(33)$ & $0.9281(33)$ \\
\hline
\end{tabular}

The second example is 69-node RDN. The base case results are $224.94 \mathrm{~kW}, 102.19 \mathrm{kVAr}$, the minimum voltage 0.9091 p.u. at node number $65, \mathrm{VSI}_{\min }=0.8278$ at node number 65 . Table II shows the outcomes of 33-node RDN after placement of three DGs using ABC, FF, GA and PSO algorithms. The locations of DGs are 18,61 and 63.

Table II. Outcomes of 69-node RDN

\begin{tabular}{|c|c|c|c|c|}
\hline $\begin{array}{l}\text { Three } \\
\text { DGs by } \\
\text { the } \\
\text { algorithm }\end{array}$ & $\begin{array}{l}\text { Total } \\
\text { DG } \\
\text { size } \\
\text { (MW) }\end{array}$ & $\begin{array}{l}\text { Real } \\
\text { Power } \\
\text { Loss } \\
(\mathrm{kW})\end{array}$ & $\begin{array}{l}\text { Minimum } \\
\text { voltage } \\
\text { (p.u.) and } \\
\text { Node } \\
\text { number }\end{array}$ & $\begin{array}{l}\text { VSI and Node } \\
\text { number }\end{array}$ \\
\hline $\mathrm{ABC}$ & 2.30 & 68.92 & $0.9815(65)$ & $0.9570(65)$ \\
\hline Firefly & 2.36 & 69.24 & $0.9765(65)$ & $0.9531(65)$ \\
\hline PSO & 2.41 & 69.62 & $0.9728(65)$ & $0.9474(65)$ \\
\hline GA & 2.48 & 69.97 & $0.9693(65)$ & $0.9432(65)$ \\
\hline
\end{tabular}

Table I and Table II show that the ABC algorithm gives better results compared to FF, PSO and GA algorithms.

\section{CONCLUSION}

This paper presents the application of the ABC algorithm to integrate multi-DGs with optimal sizes in RDNs using the loss sensitivity factors (LSF). The LSF has been used to find the appropriate nodes for integration of GDs in RDNs. The outcomes obtained by the proposed method for 33-node and 69-node RDNs are better than that PSO and GA algorithms. The voltage profile and VSI have also been improved using the ABC compared to FF, GA and PSO.

\section{REFERENCES}

1. Y. Almoataz, Y.G. Abdelaziz, W. El-Khattam Hegazy and M.O. Mahmoud, "Optimal planning of distributed generators in distribution networks using modified firefly method", Electric Power Components and Systems, Vol. 43, No. 3, 2015,pp. 320-333.

2. S. Naveen, S.S. Kumar and K. Rajalakshmi, "Distribution system reconfiguration for loss minimization using modified bacterial foraging optimization algorithm", International Journal of Electrical Power \& Energy Systems, Vol. 69, 2015, pp. 90-97.

3. Yuan-Kang Wu, Ching-Yin Lee, Le-Chang Liu, and Shao-Hong Tsai, "Study of reconfiguration for the distribution system with distributed generators", IEEE Transactions on Power Delivery, Vol. 25, No. 3, 2010, pp. 1678-1685.

4. P. Acharjee, and S.K. Goswami, "Expert algorithm based on adaptive particle swarm optimization for power flow analysis", Expert Systems with Applications, Vol. 36, No. 3, 2009, pp. 5151-5156.
5. Y.M. Atwa, E. El-Saadany, M.M.A. Salama, and R. Seethapathy, "Optimal renewable resources mix for distribution system energy loss minimization", IEEE Transactions on Power Systems, Vol. 25, No. 1 , 2010, pp. 360-370

6. H. Jia, W. Li, Z. Liu, Z., Y. Wang, Y. Zhang, and T. Xu, "Hierarchical Risk Assessment of Transmission System Considering the Influence of Active Distribution Network", IEEE Transactions on Power Systems, Vol. 30, No. 2, 2015, pp. 1084-1093.

7. I.A. Mohamed, and M. Kowsalya, "Optimal size and siting of multiple distributed generators in distribution system using bacterial foraging optimization", Swarm and Evolutionary Computation, Vol. 15, 2014, pp. 58-65.

8. V. V. S. N Murty, and A. Kumar, "Optimal placement of DG in radial distribution systems based on new voltage stability index under load growth", International Journal of Electrical Power \& Energy Systems, Vol. 69, 2015, pp. 246-256.

9. D.Q. Hung, and N. Mithulananthan, "Multiple distributed generator placement in primary distribution networks for loss reduction", IEEE Transactions on Industrial Electronics, Vol. 60, No. 4, 2013, pp. 1700-1708.

10. H. Doagou-Mojarrad, G.B. Gharehpetian, H. Rastegar, and J. Olamaei, "Optimal placement and sizing of DG (distributed generation) units in distribution networks by novel hybrid evolutionary algorithm", Energy, Elsevier, Vol. 54(C), 2013, pp. 129-138.

11. A.M. Imran, M. Kowsalya, and D.P. Kothari, "A novel integration technique for optimal network reconfiguration and distributed generation placement in power distribution networks", International Journal of Electrical Power \& Energy Systems, Vol. 63, 2014, pp. 461-472.

12. Rajnibala and Smarajit Ghosh, Optimal Position and Rating of DG in Distribution Networks by ABC-CS from Load Flow Solutions Illustrated by Fuzzy-PSO,” Neural Computing and Applications (Pape Number: NCAA-D-16-00863R3), DOI: 10.1007/s00521-017-3084-7.

13. D. Karaboga and B. Akay, "A comparative study of artificial bee colony algorithm", Applied Mathematics and Computation, Vol. 214, No. 1, pp. 2009,108-132

14. V. Teresko, " Reaction-Diffusion model of a honeybee colony's foraging behaviour", PPSN VI Proceedings of $6^{\text {th }}$ International Conference on Parallel Problem Solving from Nature, 2000,pp. 807-816

\section{Authors Profile}

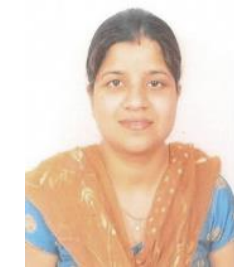

techniques.

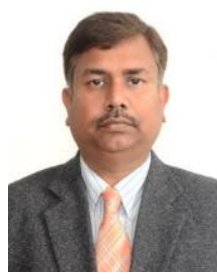

Rajni Bala is an Assistant Professor of Department of Electrical Engineering, Baba Banda Singh Bahadur Engineering college, Fatehgarh Sahib, Punjab, India. She had been awarded B.Tech. (Electrical Engineering) in 2001 and M.Tech. (Power Engineering) in 2005 from Guru Nanak Dev Engg. College Ludhiana, Punjab, India. Her research interests are in the area of Electrical Power Distribution Systems, and Soft Computing

Smarajit Ghosh is currently Professor in the Electrical and Instrumentation Engineering Department, Thapar Institute of Engineering and Technology, Patiala. Dr. Ghosh obtained his Ph.D. in 2000 from IIT, Kharagpur. Dr. Ghosh has about twenty years of teaching experience. His current area of research interest includes Load flow study, network reconfiguration, soft computing, HUD and ANC. 